Supporting Information

\title{
THE REVERSIBLE COLOR CHANGES IN LAMELLA HYBRIDS OF POLY(DIACETYLENECARBOXYLATES) INCORPORATED IN LAYERED DOUBLE HYDROXIDE NANOSHEETS
}

\author{
Toshio Itoh $^{\dagger}$, Tetsuya Shichi ${ }^{\ddagger}$, Tatsuto Yui ${ }^{\dagger}$, Hiroki Takahashi ${ }^{\dagger}$, Yoshihisa Inui ${ }^{\dagger}$ and Katsuhiko Takagi ${ }^{*},+$, \\ ${ }^{\dagger}$ Department of Crystalline Materials Science, Graduate School of Engineering \\ Nagoya University, Chikusa-ku, Nagoya 464-8603, Japan \\ ${ }^{\ddagger}$ Central Japan Railway Company, Komaki, Aichi 485-0801, Japan \\ ${ }^{\S}$ CREST, JST (Japan Science and Technology)
}

\section{(P. $31.12-1.24$ of the text)}

Synthesis of Diacetylenecarboxylic Acid. Mono-[5,11]: $\mathrm{mp}$ 46-48 ${ }^{\circ} \mathrm{C},{ }^{1} \mathrm{H}-\mathrm{NMR}(\mathrm{Me}$ ester derivative, vs TMS) $: \delta 0.90(\mathrm{t}, J=7.0 \mathrm{~Hz}, 3 \mathrm{H}), 1.24-1.40(\mathrm{~m}, 14 \mathrm{H}), 1.48-1.66(\mathrm{~m}, 6 \mathrm{H})$, $2.25(\mathrm{t}, J=7.0 \mathrm{~Hz}, 4 \mathrm{H}), 2.31(\mathrm{t}, J=7.5 \mathrm{~Hz}, 2 \mathrm{H}), 2.30(\mathrm{t}, J=7.5 \mathrm{~Hz}, 2 \mathrm{H})$, and $3.67(\mathrm{~s}, 3 \mathrm{H})$, combustion analysis, obsd. C : 78.5\%, H : 10.5\% (calcd. for C : 78.9\%, H : 10.6\%, O : 10.5\%). Mono-[10,5]: $\operatorname{mp~} 45-47{ }^{\circ} \mathrm{C},{ }^{1} \mathrm{H}-\mathrm{NMR}$ (Me ester derivative, vs TMS) : $\delta 0.88(\mathrm{t}, J=7.0 \mathrm{~Hz}$, $3 \mathrm{H}), 1.22-1.42(\mathrm{~m}, 14 \mathrm{H}), 1.48-1.60(\mathrm{~m}, 4 \mathrm{H}), 1.74(\mathrm{~m}, J=7.5 \mathrm{~Hz}, 2 \mathrm{H}), 2.24(\mathrm{t}, J=7.0 \mathrm{~Hz}, 2 \mathrm{H})$, 2.28(t, $J=7.0 \mathrm{~Hz}, 2 \mathrm{H}), 2.33(\mathrm{t}, J=7.5 \mathrm{~Hz}, 2 \mathrm{H})$, and $3.67(\mathrm{~s}, 3 \mathrm{H})$, combustion analysis, obsd. C : 77.3\%, H : 10.0\% (calcd. for $\mathrm{C}: 78.6 \%, \mathrm{H}: 10.4 \%, \mathrm{O}: 11.0 \%$ ). Mono-[10,11]: mp

54-55 ${ }^{\circ} \mathrm{C},{ }^{1} \mathrm{H}-\mathrm{NMR}$ (Me ester derivative, vs TMS) : $\delta 0.88(\mathrm{t}, J=7.0 \mathrm{~Hz}, 3 \mathrm{H}), 1.22-1.42(\mathrm{~m}$, $26 \mathrm{H}), 1.46-1.66(\mathrm{~m}, 6 \mathrm{H}), 2.24(\mathrm{t}, J=7.0 \mathrm{~Hz}, 4 \mathrm{H}), 2.31(\mathrm{t}, J=7.5 \mathrm{~Hz}, 2 \mathrm{H})$, and $3.67(\mathrm{~s}, 3 \mathrm{H})$, combustion analysis, obsd. $\mathrm{C}: 79.8 \%, \mathrm{H}: 11.3 \%$ (calcd. for $\mathrm{C}: 80.2 \%, \mathrm{H}: 11.3 \%, \mathrm{O}: 8.5 \%$ ).

(P. 8 1. 2 - 9 1. 2)

Coloration of the Poly-[5,11]/LDH Hybrid. UV irradiation of the mono-[5,11]/LDH hybrid induced a change in color from yellow to orange, as shown by the diffuse reflectance UV-Vis absorption spectra. The absorption intensities increased with an increase in the UV light irradiation time while saturation occurred after further irradiation of 3-10 min, as shown in Figure S1.

[Insert Fig. S1 here] 
The poly-[5,11]/LDH hybrid powder including guest molecules equivalent to the anion exchange capacity, i.e., 100\%-poly-[5,11]/LDH, was irradiated for $3 \mathrm{~min}$ and developed a pale yellow color, while for the 150\%-, 200\%-, and 300\%-poly-[5,11]/LDH hybrid powders, a pale yellow, yellow and red coloring gradually appeared, respectively. Figure S1 shows that the absorption maximum shifts to longer wavelengths with an increase in the amount of mono-[5,11] intercalated into the LDH hybrids. The 200\%- (Figure S1c) and 300\%-poly$[5,11] /$ LDH hybrids (Fig. S1d) consist of a mixture of a few colored components, i.e., yellow $\left(\lambda_{\max }=c a .320 \mathrm{~nm}\right)$, red $\left(\lambda_{\max }=c a .500 \mathrm{~nm}\right)$, purple $\left(\lambda_{\max }=c a .580 \mathrm{~nm}\right)$ and blue phases $\left(\lambda_{\max }\right.$ $=c a .640 \mathrm{~nm})$ in variable ratios. UV irradiation of the 300\%-poly-[5,11]/LDH hybrid for $>1$ min resulted in a spectral shift toward longer wavelengths. The progress of the polymerization was accompanied by a partial collapse of the all-trans conformation of the alkyl chains for the LDH hybrids. These results were supported by analysis showing a broadening of a series of $(00 l)$ XRD diffraction peaks for the poly-[5,11]/LDH hybrid at the initial stage of intercalation, as shown in Figure S2.

[Insert Fig. S2 here]

The interlayer spaces for the original LDH was, thus, seen to change with the intercalation of the guest diacetylene molecules. No diffraction peaks for the XRD patterns could be seen, as shown in Figure S2b, indicating the mostly irregular packing for the 100\%poly-[5,11]/LDH hybrid, while on the other hand, a series of $(00 l)$ broad peaks (Figs. S2d and e) appears for the 200\%- and 300\%-poly-[5,11]/LDH hybrids, clearly indicating the recovery of their periodic and regular packing arrangements within the interlayers. Thus, under conditions of $>200 \%$-intercalation, a stereoregular polymerization was seen to take place within the LDH clay, and in fact, under conditions of excess amounts of intercalation, the poly-[5,11]/LDH hybrid developed a reddish purple color while retaining the regularly packed conformation of the original mono-[5,11].

(P. 9 1. 3 - 1. 14)

Polymerization Degrees $\left(\mathrm{N}_{\mathrm{D}}\right)$ of Poly-[m,n] in the LDH Hybrids by Gel Permeation 
Chromatography. After $\gamma$-ray irradiation of the mono-[m,n]/LDH hybrid powders, the polymerization degrees $\left(\mathrm{N}_{\mathrm{D}}\right)$ of poly-[m,n] for the poly-[m,n]/LDH hybrids were measured by a GPC instrument, i.e., a Shimadzu liquid chromatograph LC-10AD and UV-Vis detector SPD-10A set at $467 \mathrm{~nm}$ wavelength, equipped with JAIGEL 2HA and 3HA GPC columns. Each of the LDH hybrids was placed in a pyrex vessel under Ar atmosphere and irradiated with $\gamma$-rays from ${ }^{60} \mathrm{Co}$ at a dose rate of $5.63 \times 10^{5} \mathrm{rad} / \mathrm{h}$ for $2 \mathrm{hrs}$ in room temperature. Two milligrams of each of the poly-[m,n]/LDH hybrids were treated with $5 \mathrm{~mL}$ of $3 \mathrm{~mol} \cdot \mathrm{dm}^{-3}$ $\mathrm{HCl}$ in order to isolate the poly-[m,n] included in the LDH interlayers by decomposing the LDH framework. The liberated poly-[m,n] were extracted with $5 \mathrm{~mL}$ chloroform 3 times, methylated with diazomethane, evaporated and dried in vacuo for $1 \mathrm{hr}$. The obtained powders were again dissolved in dried chloroform, filtrated with a disposable filter unit (Advantec Dismic PTFE $0.20 \mu \mathrm{m}$ ), and then analyzed by the aforementioned GPC apparatus. The GPC charts in Figure S3 for the poly-[16,1]/LDH, poly-[10,5]/LDH, poly-[5,11]/LDH, and poly-[10,11]/LDH hybrids characterize the rather broad dispersion of their molecular weights, irrespective of the $m$ and $n$ values.

\section{[Insert Fig. S3 here]}

The polymerization degrees $\left(\mathrm{N}_{\mathrm{D}}\right)$ were, however, quite different for each: 150: 70: 30: 8 were established as the relative $\mathrm{N}_{\mathrm{D}}$ on the basis of the standard polystyrene reference samples with a fixed $\mathrm{N}_{\mathrm{D}}(480$ and 38) for the poly-[16,1]/LDH, poly-[10,5]/LDH, poly-[5,11]/LDH, and poly-[10,11]/LDH, respectively. An especially large difference between poly$[10,11] /$ LDH and the other hybrids could clearly be observed. The coloration of the poly$[\mathbf{m}, \mathbf{n}] / \mathbf{L D H}$ hybrids was, thus, seen to be strongly influenced by the $\pi$-conjugation lengths in the polymer backbone of poly-[m,n] which was dependent on the methylene chain conformations. Morever, it should be noted here that the polymerization degree of the poly$[10,11] /$ LDH hybrid may possess values somewhat higher than those shown in Figure S3. This is because the poly-[10,11] in the LDH hybrids contain polymeric components insoluble in chloroform. 
(P. 12 1. 14 - 1. 18)

Infrared Absorption Spectroscopy Analysis. Infrared absorption spectroscopy was carried out with a Nihon Bunko JASCO FT/IR-300E Fourier transform infrared spectrometer. Each composite powder was mixed with $\mathrm{KBr}$ into tablets.

[Insert Fig. S4 here]

\section{(P. 11 1. 9)}

Relationship between the Coloring and the Morphological Changes of poly-[10,11]/LDH. The diffuse reflectance spectra showed that the bright orange color of the poly-[10,11]/LDH hybrid on heating at $90^{\circ} \mathrm{C}$ turned into purple-red on cooling at room temperature (ca. $20^{\circ} \mathrm{C}$ ). The color change between bright orange and purple-red was seen to be reversible, although the lower temperature color could not revert back completely to its original blue. The color recovery was shown at an absorption maximum of $575 \mathrm{~nm}$ where a series of the spectral changes were successively recorded after cooling at appropriate intervals, based on the spectra of the sample initially heated at $90^{\circ} \mathrm{C}$. Figure 10 shows the repeatability of the recovery for the absorbance at $575 \mathrm{~nm}$ during alternative heating and cooling procedures. Upon the cooling of the hybrid, its XRD indicated a shift of the (001) diffraction peak toward a lower angle by ca. $0.5^{\circ}$, suggesting a change in the conformation of the alkyl chains of the hybrids (Figure S5). Figure S6 shows the DSC profiles measured by two consecutive heat treatments of the poly-[10,11]/LDH hybrid. The observed endothermic temperatures are clearly coincident to those of the color changes.

[Insert Figs. S5 and S6 here]

\section{Captions}

Figure S1. The diffuse reflectance spectra of poly-[5,11]/LDH: (a) $100 \%$ AEC poly[5,11]/LDH; (b) $150 \% A E C$ poly-[5,11]/LDH; (c) $200 \% A E C$ poly-[5,11]/LDH; (d) 300\%AEC poly-[5,11]/LDH.

Figure S2. The X-ray diffraction patterns for poly-[5,11]/LDH: (a) $\mathrm{Cl}^{-}$type $\mathrm{LDH}$; (b) 
100\%AEC poly-[5,11]/LDH; (c) 150\%AEC poly-[5,11]/LDH; (d) 200\%AEC poly[5,11]/LDH; (e) 300\%AEC poly-[5,11]/LDH.

Figure S3. The GPC chart of the diacetylenecarboxylate/LDH hybrids: (a) poly[10,11]/LDH; (b) poly-[5,11]/LDH; (c) poly-[10,5]/LDH; (d) poly-[16,1]/LDH.

Figure S4. The infrared absorption spectra: (a) poly-[10,11]/LDH hybrid; (b) poly$[10,11]$.

Figure S5. The X-ray diffraction poly-[10,11]/LDH hybrid measured at: (a) ca. $20{ }^{\circ} \mathrm{C}$ (asprepared sample); (b) $100{ }^{\circ} \mathrm{C}$; and (c) after standing for a day after cooling to ca. $20^{\circ} \mathrm{C}$.

Figure S6. Differential scanning calorimetry charts of: (a) poly-[10,11]/LDH hybrid and (b) poly-[10,11] powders at heating-cooling between $40{ }^{\circ} \mathrm{C}$ and $120{ }^{\circ} \mathrm{C}$. Bold and dashed lines of each curve indicate the first and second cycles in Figure 9 of the text, respectively. 


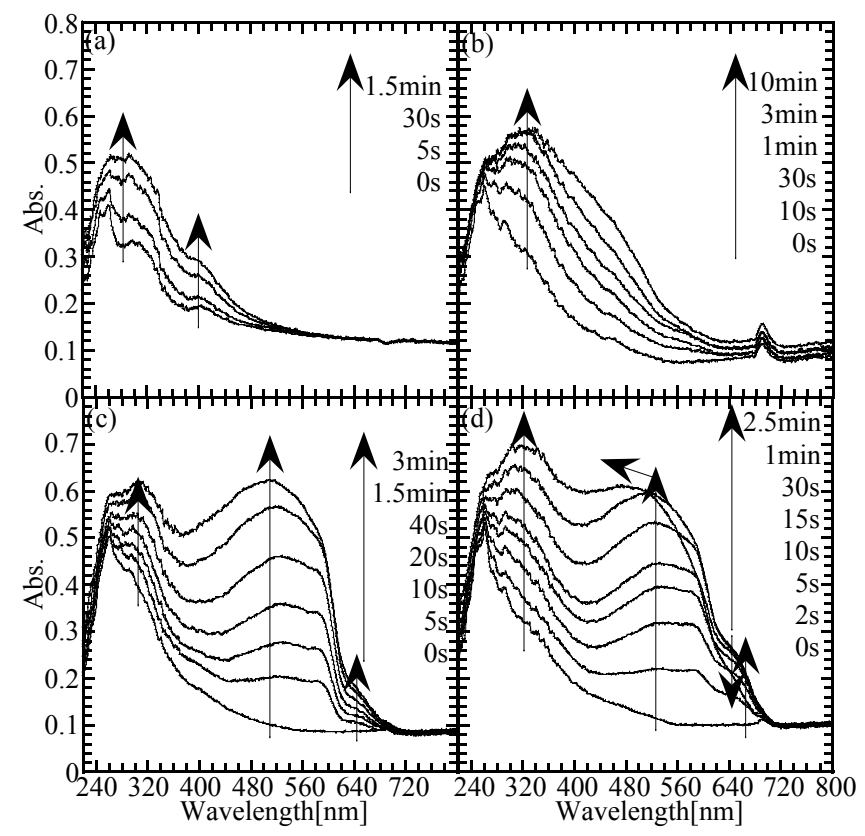

Fig.S1 


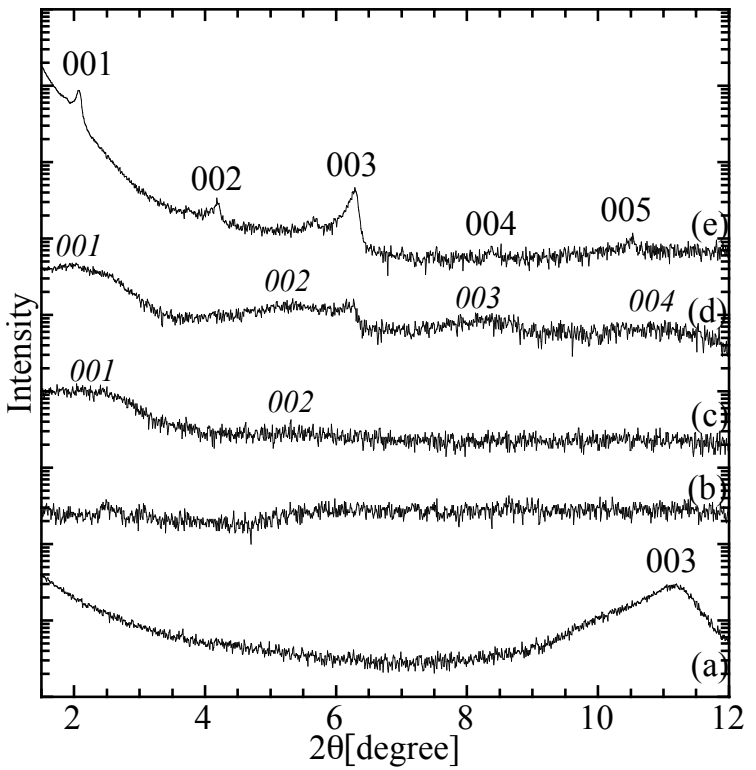

Fig.S2 


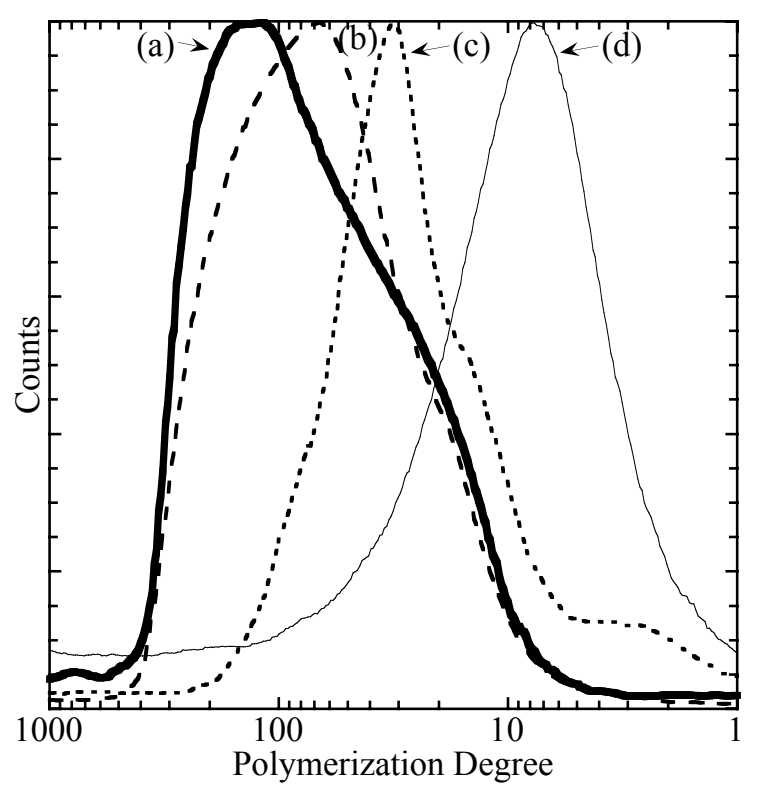

Fig.S3 


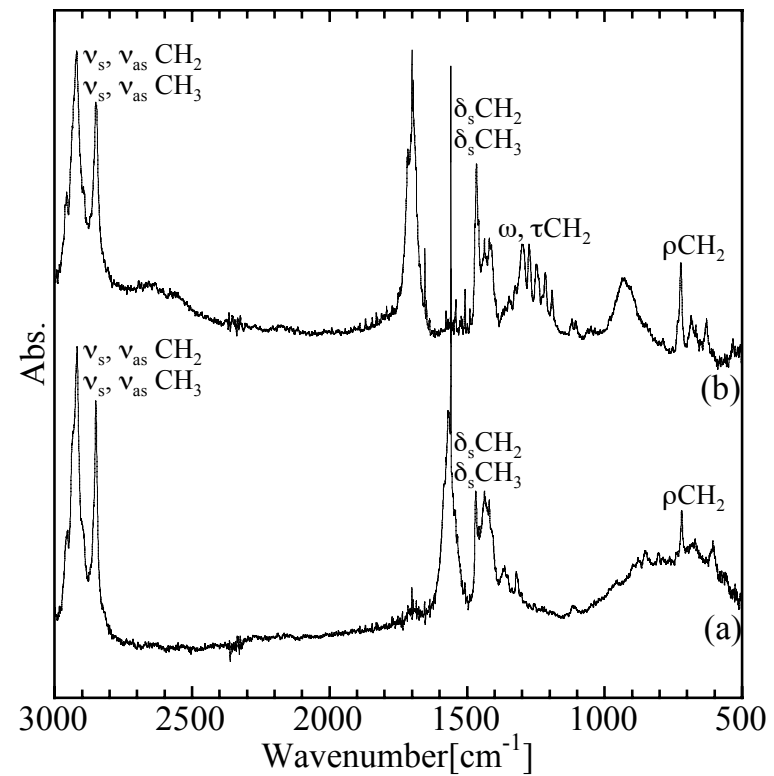

Fig.S4 


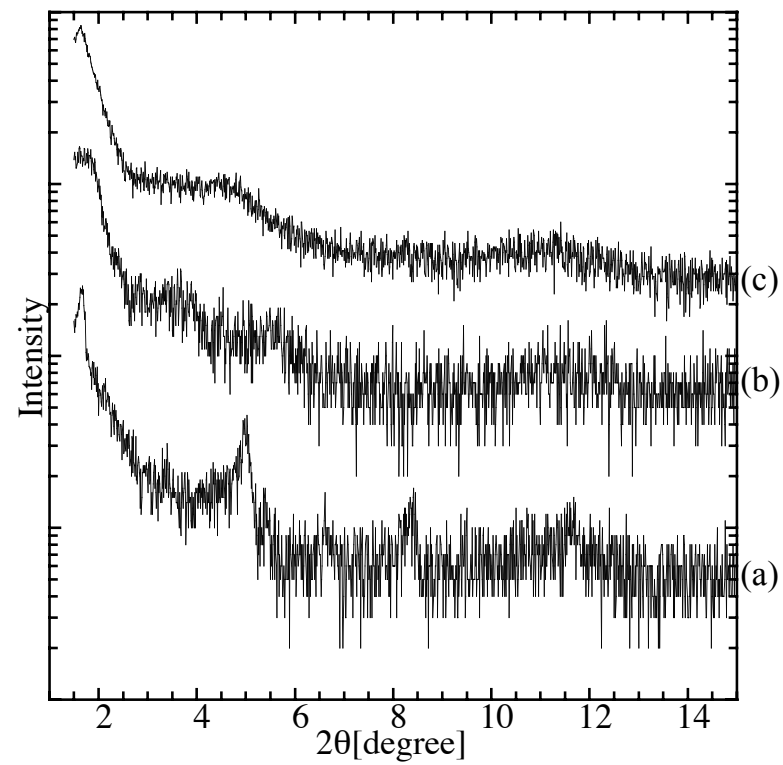

Fig.S5 

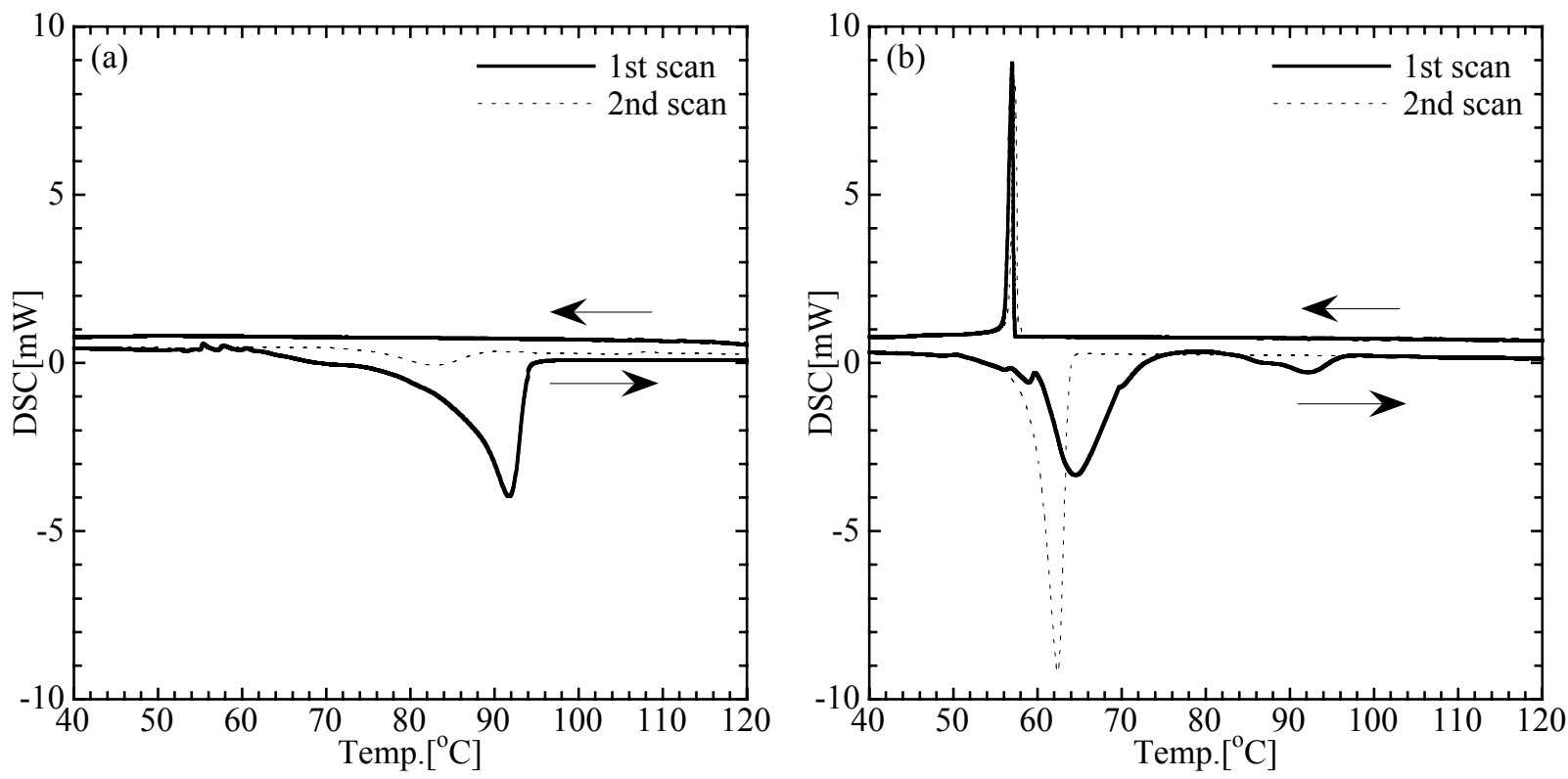

\section{Fig.S6}

